\title{
Blasts More than 10000 of Peripheral Blood White Cells
}

National Cancer Institute

\section{Source}

National Cancer Institute. Blasts More than 10000 of Peripheral Blood White Cells. NCI

Thesaurus. Code C150459.

A quantitative microscopic finding indicating that more than 10000 of the total number of nucleated cells in a peripheral leukocyte sample are immature mononuclear cells. 